Review Article

\title{
Translational control in plant antiviral immunity
}

\author{
João Paulo B. Machado $^{1 *}$, Iara P. Cali1 ${ }^{1 *}$, Anésia A. Santos ${ }^{2}$ and Elizabeth P.B. Fontes ${ }^{1}$ \\ ${ }^{1}$ Department of Biochemistry and Molecular Biology, BIOAGRO, National Institute of Science and \\ Technology in Plant-Pest Interactions, Universidade Federal de Viçosa, 36571.000, Viçosa, MG, Brazil. \\ ${ }^{2}$ Department of General Biology, Universidade Federal de Viçosa, 36571.000, Viçosa, MG, Brazil
}

\begin{abstract}
Due to the limited coding capacity of viral genomes, plant viruses depend extensively on the host cell machinery to support the viral life cycle and, thereby, interact with a large number of host proteins during infection. Within this context, as plant viruses do not harbor translation-required components, they have developed several strategies to subvert the host protein synthesis machinery to produce rapidly and efficiently the viral proteins. As a countermeasure against infection, plants have evolved defense mechanisms that impair viral infections. Among them, the hostmediated translational suppression has been characterized as an efficient mean to restrict infection. To specifically suppress translation of viral mRNAs, plants can deploy susceptible recessive resistance genes, which encode translation initiation factors from the elF4E and elF4G family and are required for viral mRNA translation and multiplication. Additionally, recent evidence has demonstrated that, alternatively to the cleavage of viral RNA targets, host cells can suppress viral protein translation to silence viral RNA. Finally, a novel strategy of plant antiviral defense based on suppression of host global translation, which is mediated by the transmembrane immune receptor NIK1 (nuclear shuttle protein (NSP)-Interacting Kinase1), is discussed in this review.
\end{abstract}

Keywords: Translation suppression, recessive resistance genes, Argonaute, NSP-Interacting Kinase, NIK.

Received: April 06, 2016; Accepted: September 27, 2016.

\section{Introduction}

Due to their sessile nature, plants are constantly exposed to extreme adverse conditions that affect negatively their growth and development, thereby resulting in considerable yield losses worldwide. Among the biotic factors, virus infections are one of the most prevalent agricultural constraints as they often suppress the plant defenses and severely limit productivity of relevant crops, representing a serious threat to global food security. As obligatory intracellular parasites, plant viruses depend on the host cell machinery to replicate their genome, express their genes and invade their hosts. Thus, in order to establish a productive infection, compatible interactions between viral and host factors must occur, from the expression and replication of the viral genome until the cell-to-cell movement and long distance translocation through the vascular system of viral particles. In addition to providing basic compatibility, interactions between viral and host proteins are necessary to

Send correspondence to Elizabeth P B Fontes. Department of Biochemistry and Molecular Biology, BIOAGRO, National Institute of Science and Technology in Plant-Pest Interactions, Universidade Federal de Viçosa, Av. PH Rolfs s/n, 36571.000, Viçosa, MG, Brazil. Email: bbfontes@ufv.br

${ }^{\star}$ These authors contributed equally to this work. modulate the viral infection, preventing or neutralizing the plant defense mechanisms.

Plants deploy several strategies to defend themselves against viral infections; the best characterized are the expression of resistance genes and RNA silencing (Nicaise, 2014). Naturally occurring resistance genes, which show dominant or recessive inheritance, bestow an efficient barrier to viral infection (Robaglia and Caranta, 2006). Most of the dominant resistance genes ( $\mathrm{R}$ genes) identified in plant-virus interactions belong to the nucleotide binding site leucine-rich repeat (NBS-LRR) class, which specifically recognize viral avirulence (avr) gene products (De Ronde et al., 2014; Galvez et al., 2014; Nicaise, 2014). Frequently, the $\mathrm{R}$ protein activation elicits a hypersensitive response (HR), which is often associated with programmed cell death of infected and adjacent cells, confining the pathogen within the local site of infection (Gururani et al., 2012; Galvez et al., 2014). The downstream events of $\mathrm{R}$ protein activation might be also associated with other signals like influx of $\mathrm{Ca}^{2+}$ ions from the extracellular space and/or anion flux, MAPK-mediated signaling, production of reactive oxygen species (ROS), salicylic acid (SA) accumulation, extensive transcriptional reprogramming and activation of defense responses (Gururani et al., 2012; Nicaise, 2014). Additionally to dominant $R$ gene-related resistance responses, recessive resistance has been com- 
monly reported in viral systems as another evolving strategy to impair virus infection (Kang et al., 2005b). Instead of triggering typical defense responses, like the hypersensitive response, most recessive mutations lead to a nonpermissive environment due to the lack of appropriate host factors, which are required for the viruses to complete their biological cycle (Ritzenthaler, 2005; Galvez et al., 2014). In contrast to dominant resistance, recessive resistance seems to be more durable because the viruses can only overcome the host resistance response by adapting themselves to the missing factors (Ritzenthaler, 2005; Truniger and Aranda, 2009). Because viruses do not encode translational functions and depend exclusively on the host cell machinery to synthesize the viral proteins, it is not surprising that a large number of recessive resistance genes have been mapped to mutations in translation initiation factors (eIFs) belonging to the eIF4E and eIF4G family or their isoforms eIF(iso)4E and eIF(iso)4G (Truniger and Aranda, 2009; Wang and Krishnaswamy, 2012; Julio et al., 2015). In general, these mutations prevent the interactions between host factors and viral RNAs and/or proteins, which otherwise would recruit the host apparatus of translation for the synthesis of viral proteins. The partial functional redundancy of isoforms from the eIF4E and eIF4G families allows loss-of-function mutations of one isoform to provide virus resistance without compromising the general growth performance of the plant.

RNA silencing also represents a well-documented antiviral mechanism in plants (Ding, 2010; Pumplin and Voinnet, 2013; Csorba et al., 2015; Ghoshal and Sanfaçon, 2015). Viral RNAs can be addressed for degradation via the endonucleolytic activity of argonaute (AGO), the catalytic component of the RNA-induced silencing complex (RISC; Mallory and Vaucheret, 2010). In addition to the endonucleolytic cleavage, recent evidence has demonstrated that the mechanism of antiviral RNA silencing also operates by suppressing viral mRNA translation (Ghoshal and Sanfaçon, 2015). As a virulence strategy, plant viruses have evolved mechanisms to prevent RNA silencing-mediated defense, predominantly by synthesizing silencing suppressors (Bologna and Voinnet, 2014; Carbonell and Carrington, 2015).

In addition to translational defense mechanisms based on recessive resistance and RNA silencing, a novel strategy of translational suppression in plant defense against DNA viruses (begomoviruses) has recently emerged as a new paradigm of antiviral defenses in plants. In this case, the activation of the transmembrane immune receptor NIK1 [nuclear shuttle protein (NSP)-interacting kinase 1] promotes the down-regulation of translational machineryassociated genes, culminating in the inhibition of viral and host mRNAs translation, which causes an increase in tolerance to begomoviruses (Zorzatto et al., 2015). These defense strategies against viruses strengthen the argument that the inhibition of translation of viral proteins or their ca- pacity to interact with translational factors offer promising alternatives to control viruses in plants.

\section{Recessive resistance genes in translational control}

Plants respond to pathogens through an elaborate network of genetic interactions and the outcome of these interactions can result in disease or resistance. Among the plant resistance genes, the recessive ones play relevant roles in plant defense against viruses and comprise about one-half of known antiviral resistance genes (Sanfaçon, 2015). Recessive resistance is frequently associated with the lack of host factors necessary for the completion of the virus biological cycle (Galvez et al., 2014). In order to achieve a successful infection, the viruses not only need unrestricted access to the host translation machinery to synthesize their proteins, but they also need to suppress host innate defenses, which may act to impair the protein production capacity of the infected cells (Walsh and Mohr, 2011). The majority of recessive genes involved in plant-virus interactions encode eukaryotic translation initiation factors (eIFs) of the $4 \mathrm{E}$ or $4 \mathrm{G}$ family, mainly eIF4E, eIF4G and their isoforms (Kang et al., 2005b; Truniger and Aranda, 2009; Wang and Krishnaswamy, 2012). The involvement of eIF4E and eIF4G was firstly reported in potyvirus infection and subsequently expanded to include other plant virus families, such as bymoviruses, cucumoviruses, ipomoviruses, sobemoviruses, carmoviruses, and waikiviruses, suggesting that they contribute to a broad mechanism of plant susceptibility to viruses (Nicaise, 2014). In eukaryotes, mRNA translation is predominantly cap-dependent and involves the assembly of an mRNA-protein complex by different eIFs (Aitken and Lorsch, 2012; Hinnebusch, 2014). eIF4E is a cap-binding protein involved in the initiation of translation, being part of the protein complex known as eIF4F, which also contains eIF4G and the DEAD-box RNA helicase eIF4A. The eIF4F complex, comprising eIF4G, eIF4E and eF4A, binds poly(A)binding protein (PABP) and eIF3 (Jackson et al., 2010; Sanfaçon, 2015). In contrast to other eukaryotes, plants possess a second form of eIF4F, named eIF(iso)4F, which includes eIF(iso)4E and eIF(iso)4G (Patrick and Browning, 2012; Sanfaçon, 2015). eIF(iso)4F has complementary activities with eIF4F, but their respective components are differentially expressed, suggesting that they may also display distinct functions (Wang, 2015). Several resistance genes encoding a mutated form of eIF4E or eIF(iso)4E proteins have been shown to mediate resistance against viral infection in a range of plant/virus interactions. These include sbm-1 against Pea seed-borne mosaic virus (PsbMV) and cyv2 against Clover yellow vein virus (ClYVV) in pea; mol(1), mol(2) in lettuce against Lettuce mosaic virus (LMV); pvr1, pvr2 and pvr6 in pepper against Tobacco etch virus (TEV), Potato virus Y (PVY), Pepper veinal mottle 
virus (PVMV); rym4 and rym5 in barley against Barley yellow mosaic virus (BaYMV); nsv in melon against Melon necrotic spot virus (MNSV); pot-1 in tomato against PVY and TEV; 1sp1 in Arabidopsis against Turnip mosaic virus (TuMV) and TEV (Lellis et al., 2002; Ruffel et al., 2002, 2005, 2006; Nicaise et al., 2003; Gao et al., 2004a,b; Kang et al., 2005a; Stein et al., 2005; Albar et al., 2006; Nieto et al., 2006; Andrade et al., 2009). Additionally, genes encoding a mutated form of eIF4G or its defective isoforms, such as rymv1 and tsv1, are responsible for resistance to Rice yellow mottle virus (RYMV) and Rice tungro spherical virus (RTSV) in rice (Albar et al., 2006; Lee et al., 2010). The cum1 and cum 2 mutations, coding for translation initiation factors $4 \mathrm{E}$ and $4 \mathrm{G}$, respectively, inhibit Cucumber mosaic virus (CMV) multiplication and Turnip crinkle virus (TCV) in Arabidopsis (Yoshii et al., 2004).

An important step on the elucidation of the molecular nature of recessive resistance was the identification of VPg (genome-linked viral protein) from several potyviruses as an interacting partner of the translation initiation factor $4 \mathrm{E}$ (eIF4E) or its isoform eIF(iso)4E in yeast two-hybrid and in vitro binding assays (Figure 1) (Wittmann et al., 1997; Léonard et al., 2000; Schaad et al., 2000; Lellis et al., 2002; Robaglia and Caranta, 2006). Mutations in VPg, which disrupt VPg-eIF(iso)4E interaction, impair viral infection in planta (Léonard et al., 2000). The VPg protein may act mimicking the 5'-cap structure of messenger RNAs and recruiting the translation complex for viral genome translation through its specific interaction with eIF4E/eIF(iso)4E (Michon et al., 2006; Wang, 2015). Thus, VPg protein facilitates viral RNA translation by competing with the eIF4E/eIF(iso)4E cap binding activity and enhancing the affinity of eIF4E/eIF(iso)4E for viral RNAs in vitro. (Plante et al., 2004; Khan et al., 2008). The host factor eIF4G/eIF(iso)4G is also important for a potyvirus infection as it enhances VPg-eIF4E/eIF(iso)4E interactions (Nicaise et al., 2007). The VPg protein of Rice yellow mot-

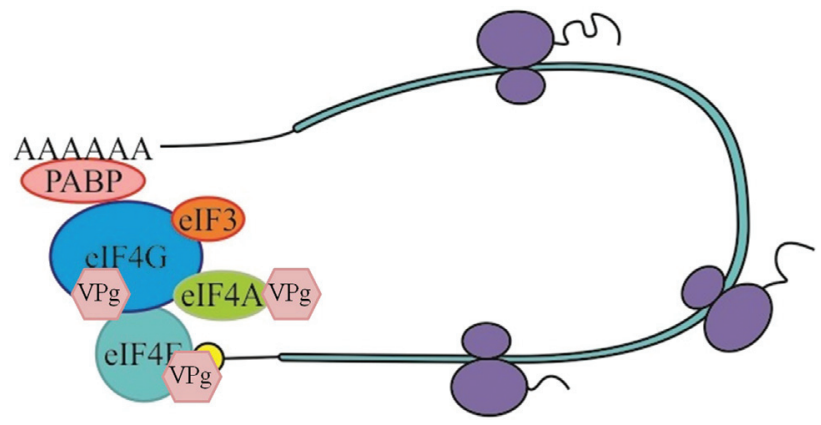

Figure 1 - Host translation factors targeted by genome-linked viral protein (VPg) in canonical eukaryotic translation. VPg recruits the translation initiation complex for viral genome translation through its specific interaction with eIF4E/eIF(iso)4E. VPg also binds to eIF4G/eIF(iso)4G, which may act enhancing VPg-eIF4E/eIF(iso)4E interactions. Potyvirus VPg protein interacts with DEAD-box RNA helicase-like proteins closely related to $A$. thaliana eIF4A genes. RNA helicase, as part of the eIF4F translation complex, might be also involved in viral genome replication. tle virus (RYMV) binds directly to eIF(iso)4G, rather than to eIF4E isoforms (Hebrard et al., 2010). These observations suggest that VPg recruits the whole eIF4F complex, possibly for the translation of viral RNAs (Sanfaçon, 2015).

Although the VPg-eIF4E/iso4E complex may support viral RNA translation in some potyvirus-host interactions, it probably contributes to other steps of the infection. Accordingly, Tobacco etch virus (TEV) has been demonstrated to depend on eIF(iso)4E for its systemic spread in Arabidopsis, suggesting a role of eIF(iso) $4 \mathrm{E}$ in viral movement (Contreras-Paredes et al., 2013). This interpretation was consistent with the observation that inactivation and overexpression of the $e I F$ (iso) $4 E$ gene did not affect global cellular or viral translation and, in the null mutant, viral replication was still observed. These results indicate that, for the TEV-Arabidopsis system, eIF(iso)4E is not required for viral translation and replication in the viral infective cycle, but is required for viral movement, as TEV systemic spread was completely abolished in the eif(iso) $4 f$ knockout lines.

Other components of the host translation machinery, such as eEF1A and PABP, are found in the virus translation/replication complex (Beauchemin and Laliberte, 2007; Thivierge et al., 2008; Wang, 2015). eEF1A, eEF1B and an eIF3 subunit are required for TMV infection (Osman and Buck, 1997; Yamaji et al., 2006; Hwang et al., 2013). The RNA of Turnip yellow mosaic virus (TYMV) possesses a tRNA-like structure at 3' UTR instead of a poly(A) tail, which works as a translation enhancer of the viral RNA. This region interacts with the host factor eEF1A and seems to regulate viral replication (Matsuda and Dreher, 2004; Sanfaçon, 2015). The ribosomal protein $\mathrm{P} 0$ has been correlated with viral RNA translation in Potato virus A (PVA) infection (Hafren et al., 2013). Huang et al. (2010) have reported the identification of two VPg-interacting plant DEAD-box-containing RNA helicase-like proteins, AtRH8 from Arabidopsis and PpDDXL from peach (Figure 1). These proteins share sequence homology with eIF4A, a component of the eIF4F multiprotein complex. AtRH8 is not required for plant growth and development, but is necessary for viral infection. Arabidopsis atrh $8 \mathrm{mu}-$ tant plants were resistant to both plant potyviruses Plum pox virus (PPV) and TuMV.

Additionally to their roles in the host translation of mRNAs, translation factors play other biological functions that might be exploited by viruses. eIF4E has been shown to accumulate in nuclear bodies, where it is involved in the export of a subset of mRNAs containing a structure known as a 4E-sensitivity element (Goodfellow and Roberts, 2008, Truniger and Aranda, 2009). In this context, it would be possible that VPg acts in the nucleus suppressing eIF4E-mediated mRNA exportation to the cytoplasm (Wang and Krishnaswamy, 2012). This hypothesis is supported by the observation that VPg inhibits the translation of the capped mRNAs (Khan et al., 2008; Eskelin et al., 
2011). eIF4E-VPg complex may be also involved in the suppression of RNA silencing, in which VPg acts as an accessory factor for HC-Pro (silencing suppressor protein) and promotes disturbance of siRNA and microRNA processing in the nucleus (Kasschau and Carrington, 1998; Rajamäki and Valkonen, 2009).

\section{Antiviral roles of plant argonautes in translation repression and virus countermeasures}

Argonautes (AGOs) are the effector proteins functioning in eukaryotic RNA silencing pathways (Carbonell and Carrington, 2015; Fang and Qi, 2016), a sequencespecific process that serves two main functions: regulation of gene expression and defense against pathogens (Mandadi and Scholthof, 2013; Bologna and Voinnet, 2014; Nicaise, 2014; Zhang et al., 2015; Wang and Chekanova, 2016). RNA silencing is triggered by the presence of double-stranded RNA (dsRNA), which is processed into small RNA (sRNA) molecules of 21-24 nucleotide (nt) by RNase III-type enzymes called Dicer, or Dicer-like (DCL) in plants (Figure 2; Krol et al., 2010). Upon processing, one strand of the sRNA duplexes is incorporated into RNA-induced silencing complexes (RISCs), whose key catalytic component corresponds to one member of the AGO protein family. Once integrated into the RISC, sRNAs guide the sequence-specific inactivation of the targeted RNA or DNA (Kamthan et al., 2015). The mechanisms of action of AGO/sRNA complexes at the RNA level include mRNA cleavage or translational repression (post-transcriptional gene silencing, PTGS; Figure 2), whereas, at the DNA level, they involve DNA and/or histone methylation and subsequent transcriptional gene silencing (TGS) (Martinez de Alba et al., 2013).

Translational repression guided by sRNAs has been best studied in fly and mammalian cells and is mediated by imperfect base pairing of microRNAs (miRNAs) to target mRNAs (Wilczynska and Bushell, 2015). In animal cells, miRNAs normally bind to the 3'-untranslated region (3'UTR) of target mRNAs and direct not only translation repression but also mRNA destabilization, which are initiated by deadenylation/decapping enzymes. Both processes require association of AGO proteins with proteins containing glycine-tryptophan (GW/WG) motifs, such as members of the GW182 family (Fukaya and Tomari, 2012; Pfaff and Meister, 2013). In plants, early studies have shown that miRNAs display a high degree of sequence complementarity to their target mRNAs and they guide cleavage of target RNAs through endonucleolytic activity of AGO1 (Tang et al., 2003; Baumberger and Baulcombe, 2005). This led to the assumption that RNA cleavage is the major mode of action of plant miRNAs (Jones-Rhoades et al., 2006; Huntzinger and Izaurralde 2011). However, recent reports suggest that plant miRNAs mediate not only the cleavage of the target but also a concurrent translation repression

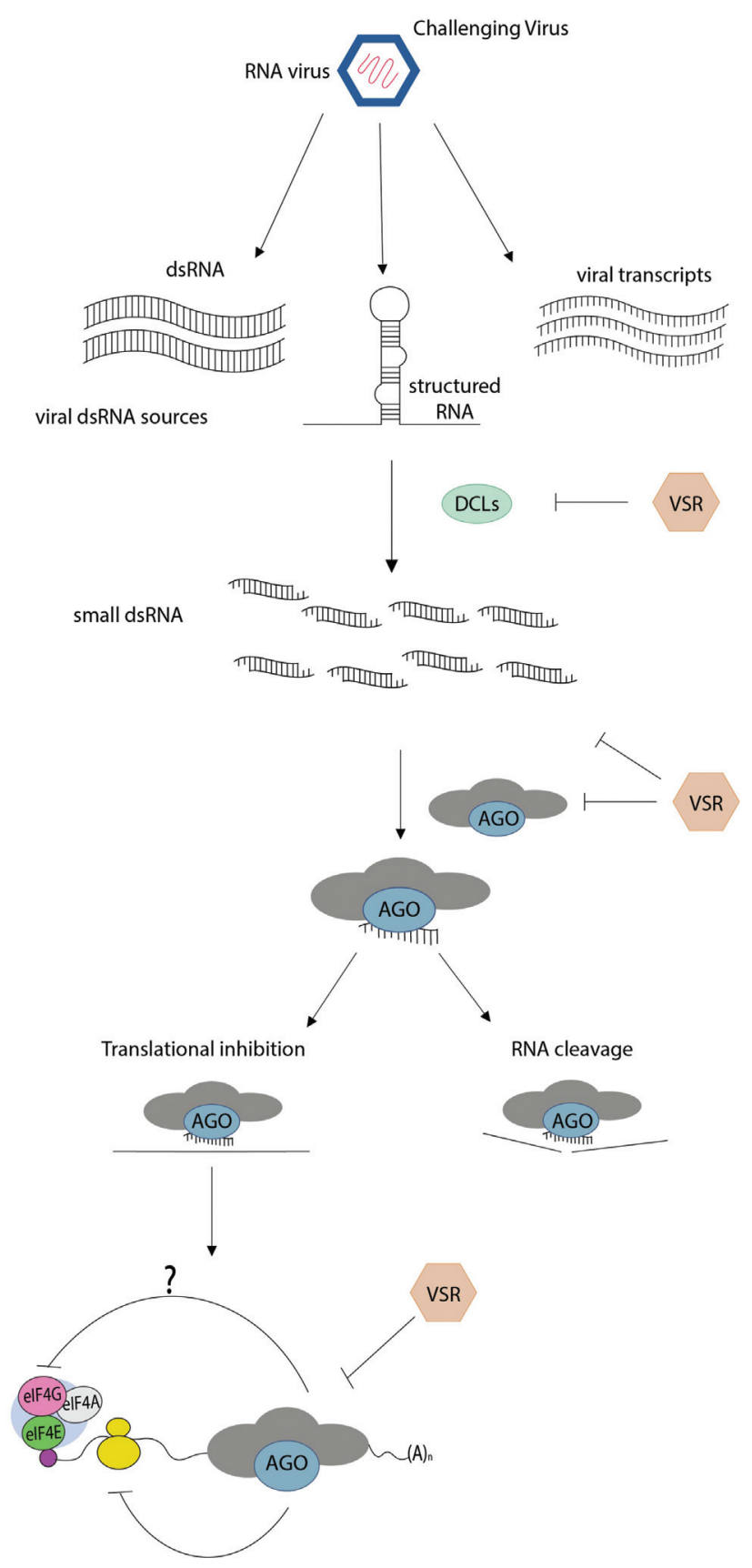

Figure 2 - An integrating overview of RNA silencing and AGO-mediated translational repression of mRNA targets. RNA silencing is launched by viral double-stranded RNAs (dsRNAs) from different sources, which are processed into small interfering RNA molecules of 21-24 nucleotide (nt) by Dicer-like (DCL) proteins. Subsequently one strand of the siRNA duplexes is loaded into RNA-induced silencing complexes (RISCs) harboring an argonaute (AGO) effector protein. In light of post-transcriptional gene silencing (PTGS), AGO/sRNA complexes trigger viral RNA cleavage or translational repression. Although unclear, translation repression directed by sRNAs in plants seems to rely on AGO activity, which may act targeting ribosome assembly, interfering with $48 \mathrm{~S}$ initiation complex formation, or translational initiation factors (eIFs). The AGO-RISC complex is further capable of repressing translation by preventing translation elongation or ribosomal recruitment. Viral suppressors of RNA silencing (VSRs) interfere in multiple steps of the antiviral RNA silencing pathway, including dicing inhibition, viral RNA loading, AGO inactivation and suppression of its translational inhibitory activity. 
(Brodersen et al., 2008; Lanet et al., 2009; Yang et al., 2012; Iwakawa and Tomari, 2013; Li et al., 2013). Evidence that miRNAs repress translation in plants emerged from the examination of protein accumulation from miRNA-targeted genes (Aukerman and Sakai, 2003; Chen, 2004; Gandikota et al., 2007). In these studies, plant miRNAs were found to exert disproportionate effects on target gene expression at mRNA versus protein levels. Furthermore, mutations in a number of genes, including the $\mathrm{P}$ body component VARICOSE (VCS) and ALTERED MERISTEM PROGRAM1 (AMP1), an integral membrane protein associated with endoplasmic reticulum (ER) and AGO1, impair miRNA-mediated target repression at the protein but not at the mRNA level (Brodersen et al., 2008; Li et al., 2013). Additional evidence for the miRNAmediated translational repression in plants came from the observation that AGO1 and several miRNA are associated with polysomes (Llave et al., 2002).

AGO1, AGO2 and AGO10 have been implicated in translation repression (Brodersen et al., 2008; Lanet et al., 2009; Fátyol et al., 2016). Mutations in AGO1 and AGO10 genes impair miRNA-mediated target repression at the protein but not at the mRNA level (Brodersen et al., 2008). Furthermore, by using an in vitro system prepared from plant cultured cells, AtAGO1 has been shown to have the ability to repress translation initiation even when the cleavage of mRNA targets was blocked by introducing central mismatches in the miRNA-target pairing region or mutation of the catalytic core of AtAGO1 (Iwakawa and Tomari, 2013). Recently, Fátyol et al. (2016) showed, using a sensitive transient in vivo reporter system, that $\mathrm{AGO} 2$ is capable of exerting translational repression in various miRNA target site constellations (Open reading frame - ORF, 3'UTR).

The mechanism of AGO-mediated translational repression in plant cells is less clear than in animal cells. Although plant cells apparently lack orthologs of GW182 (Huntzinger and Izaurralde 2011), which are proteins containing GW/WG motifs required for AGO-mediated translation suppression in animal cells (Fukaya and Tomari, 2012; Pfaff and Meister, 2013), the Arabidopsis SUO protein (a large protein with two C-terminal GW motifs) is required for miRNA directed translation repression and may serve as a functional analog of the GW182 proteins (Yang et al., 2012). In line with the notion that plants likely lack orthologs of GW182, deadenylation of the mRNAs has not been observed in tobacco cell lysates (Iwakawa and Tomari, 2013). Binding of miRNAs is not only restricted to the 3'UTR of the mRNAs but also occurs in the 5'UTR and even in the ORF (Iwakawa and Tomari, 2013; Fátyol et al., 2016). A detailed in vitro study revealed that several distinct types of translation repression could be mediated by plant miRNAs depending on the position of the target sites (Iwakawa and Tomari, 2013). When target sites reside in the 3'UTR of the mRNAs, AtAGO1-RISC is capable of re- pressing translation initiation by interfering with 48S initiation complex formation, a mechanism similar to that observed in animal cells (Figure 2). Binding of miRNAs to targets within the ORF functions differently by preventing translation elongation (Iwakawa and Tomari, 2013). When extensively complementary target sites reside in the 5'UTR, AtAGO1-RISC can sterically hinder ribosomal recruitment (Iwakawa and Tomari, 2013).

Antiviral RNA silencing is triggered by highly structured viral ssRNA or dsRNA, which are recognized and processed by DCLs to produce viral small interfering RNAs (vsiRNAs) that are subsequently incorporated into antiviral RISCs (Mallory and Vaucheret, 2010). Antiviral AGOs associate with vsiRNAs and target complementary viral RNAs for degradation through endonucleolytic cleavage (slicing) and/or for translational arrest, transcriptionally repress complementary viral DNA through hypermethylation, or regulate host gene expression to promote defense (Szittya and Burgyan, 2013). These processes can result in a phenomenon known as recovery, whereby the plant silences viral gene expression and recovers from viral symptoms. The targeting of viral RNAs is thought to largely involve RNA cleavage. Nevertheless, recent studies have identified AGO-mediated translation repression as an additional RNA silencing mechanism against plant viruses (Bhattacharjee et al., 2009; Ghoshal and Sanfaçon, 2014; Karran and Sanfaçon, 2014; Ma et al., 2015).

Translational repression of viral mRNAs was first observed in association with the defense response activated by the interaction between a dominant resistance gene and a viral elicitor (Bhattacharjee et al., 2009). Co-expression of a resistance protein with nucleotide-binding (NB) and leucine-rich repeat (LRR) domain (NB-LRR) and its cognate viral effector results in an antiviral response that inhibits the translation of virus-encoded proteins in Nicotiana benthamiana (Bhattacharjee et al., 2009). Both the translational repression of viral transcripts and NB-LRRmediated virus resistance were impaired by the downregulation of Argonaute 4-like genes. These results suggest that AGO proteins are involved in the specific translational control of viral transcripts in virus resistance mediated by NB-LRR proteins (Bhattacharjee et al., 2009). Translation inhibition was also observed in a study with Tobacco rattle virus (TRV) in Arabidopsis (Ma et al., 2015). In this study, recovered plants showed reduced association of TRV RNAs with ribosomes and an increase in the formation of RNA processing bodies (PBs). Another example of AGOdependent translational repression mechanism was observed in $N$. benthamiana plants infected with Tomato ringspot virus (ToRSV) (Ghoshal and Sanfaçon, 2014). In this interaction, symptom recovery follows an initial symptomatic systemic infection. These authors also showed that the recovery of ToRSV-infected plants is associated with a reduction in the steady-state levels of viral proteins and decreased translation of the corresponding viral RNA. In vivo 
labeling experiments revealed efficient synthesis of the RNA2-encoded coat protein (CP) early in infection, but reduced RNA2 translation later in infection. Additionally, neither recovery nor the reduction of RNA2 translation were observed in plants silenced for AGO1, suggesting that AGO1 plays a role in the translational repression mechanism targeting ToRSV (Ghoshal and Sanfaçon 2014).

As a counter-defense strategy against antiviral RNA silencing mechanism, most plant viruses have evolved specialized proteins known as viral suppressors of RNA silencing (VSRs), which disrupt various steps of the silencing pathway (Burgyán and Havelda 2011; Pumplin and Voinnet, 2013; Csorba et al., 2015). AGO proteins are preferred targets of VSRs at multiple levels (Figure 2). Among the well-characterized VSRs, some of them (e.g., the tombusvirus $\mathrm{p} 19$ and the potyvirus HC-Pro proteins) directly bind and sequester vsiRNA duplexes away from antiviral AGOs, preventing their loading into the RISC (Vargason et al., 2003; Ye et al., 2003; Csorba et al., 2015; Garcia-Ruiz et al., 2015). VSRs can also prevent AGO association with vsiRNAs by promoting AGO degradation, as observed for polerovirus and enamovirus. P0 proteins destabilize AGO1 through an F-box-like domain and induce subsequent degradation through the autophagy pathway (Baumberger et al., 2007; Bortolamiol et al., 2007; Csorba et al., 2010; Derrien et al., 2012; Fusaro et al., 2012). Likewise, the silencing suppressor P25 of Potato virus $X$ interacts with $\mathrm{AGO} 1$ and mediates its degradation through the proteasome pathway (Chiu et al., 2010).

VSRs can also block vsiRNA-programmed AGOs. The cucumovirus $2 \mathrm{~b}$ protein interacts directly with AGO1, and this interaction occurs primarily on one surface of the PAZ domain and part of the PIWI domain of AGO1 (Zhang et al., 2006). Consistent with this interaction, 2b specifically inhibits the AGO1 slicing activity in RISC (Zhang et al., 2006). Some VSRs, including the ipomovirus P1, carmovirus p38 and nepovirus $\mathrm{CP}$ proteins, contain WG/GW motifs that mimic AGO1-interacting cellular proteins (Azevedo et al., 2010; Giner et al., 2010; Szabo et al., 2012; Zhang et al., 2012; Karran and Sanfaçon, 2014). P1 protein from Sweet potato mild mottle virus (SPMMV) targets loaded AGO1 and inhibits the si/miRNA-programmed RISC activity. The suppressor/binding activities are localized at the $\mathrm{N}$-terminal half of $\mathrm{P} 1$, a region containing three WG/GW motifs (Giner et al., 2010). The importance of the Glycine-Tryptophan (GW) motifs in AGO1 binding and suppression activity was further demonstrated when Sweet potato feathery mottle virus (SPFMV) P1, which did not have any silencing suppressor activity, was converted into a VSR by including two additional WG/GW motifs (Szabo et al., 2012). P38 protein from Turnip crinkle virus (TCV) physically interacts through $\mathrm{GW}$ repetitive motifs with unloaded Arabidopsis AGO1 (Azevedo et al., 2010) or AGO2 (Zhang et al., 2012), suppressing RNA silencing. Another example of VSR that acts through interaction with AGO1 in a WG motif-dependent manner is ToRSV CP protein (Karran and Sanfaçon, 2014). The WG motif within the CP is required for silencing suppression, AGO1 binding, $\mathrm{CP}$ mediated AGO1 degradation, suggesting that the ToRSV $\mathrm{CP}$ acts as an AGO-hook protein and competes for AGO binding with a plant cellular GW/WG protein involved in translation repression (Karran and Sanfaçon, 2014).

\section{The translational control branch of the NIK-mediated antiviral signaling}

The immune receptor NIK1 [nuclear shuttle protein (NSP)-interacting kinase 1] has a remarkable role in the defense response against begomoviruses. It belongs to the receptor-like kinase (RLK) family of plant receptors, and it was first identified as a virulence target of the begomovirus nuclear shuttle protein (NSP) (Fontes et al., 2004). NSP is encoded by the component B, DNA-B, of bipartite begomoviruses (Geminiviridae family) that also encodes the movement protein (MP), both being viral proteins required for systemic infection (Hanley-Bowdoin et al., 2013). The proteins required for replication (Rep and REn), transactivation of viral genes (TrAP), the suppression of RNAi defense functions (TrAP and AC4) and encapsidation of viral DNA (CP) are encoded by the other genomic component, DNA-A. Begomoviruses replicate their genome in the nuclei of infected plants via rolling circle replication. NSP facilitates the traffic of viral DNA from the nucleus to the cytoplasm and acts in concert with MP to move the viral DNA to the adjacent, uninfected cells (Hanley-Bowdoin et al., 2013).

Virus propagation is usually restricted by the activation of the small interfering RNA (siRNA) antiviral machinery and/or salicylic acid (SA) signaling pathway (Nicaise, 2014). In the case of begomoviruses, it has been shown that in addition to encoding suppressors for siRNAmediated defenses, these viruses enhance their pathogenicity in susceptible hosts by suppressing the antiviral activity of the transmembrane receptor NIK1 by the viral NSP (Fontes et al., 2004; Santos et al., 2009; Brustolini et al., 2015).

Within the RLK family, NIKs receptors (NIK1, NIK2 and NIK3) belong to the subfamily II of leucine-rich repeat (LRR)-RLKs, designated LRRII-RLK group (Shiu and Bleecker, 2001; Dievart and Clark, 2004). NIK1 was identified through two-hybrid screening using the viral protein NSP as bait (Fontes et al., 2004; Mariano et al., 2004). The NSP-NIK1 interaction was further demonstrated by in vitro GST pull-down assays and confirmed in planta through bimolecular fluorescence complementation (BiFC) assays (Fontes et al., 2004; Brustolini et al., 2015). The NSP-NIK interaction is conserved among begomovirus NSPs and NIK homologues from different hosts. NIK homologs from Arabidopsis, tomato and soybean interact with NSP from Cabbage leaf curl virus (CaLCuV) and from tomato- 
infecting begomoviruses, such as Tomato golden mosaic virus (TGMV), Tomato crinkle leafyellow virus (TCrLYV) and Tomato yellow spot virus (ToYSV) (Fontes et al., 2004; Mariano et al., 2004; Sakamoto et al., 2012). Using the two-hybrid system in yeast, the NSP-binding site was mapped to an 80 amino acid stretch of the kinase domain (positions 422-502) of NIK1 that encompasses the putative active site for Ser/Thr kinases (subdomain VIb-HrDvKssNxLLD) and the activation loop (subdomain VII-DFGAk/rx, plus subdomain VIII-GtxGyiaPEY) (Fontes et al., 2004).

NSP from $\mathrm{CaLCuV}$ acts as a virulence factor to suppress the kinase activity of transmembrane receptor NIKs, suggesting that NIK is involved in antiviral defense response (Fontes et al., 2004). Several lines of evidence further support a NIK role in antiviral defense. Firstly, loss of NIK function in Arabidopsis is linked to an enhanced susceptibility phenotype to infection by a coat protein-less mutant of CaLCuV (Fontes et al., 2004; Carvalho et al., 2008; Santos et al., 2009). In addition, overexpression of NIK1 from Arabidopsis in tomato plants attenuates symptom development and delays ToYSV infection (Carvalho et al., 2008). Finally, mutations in the activation loop (A-loop) of NIK1 that block its autophosphorylation activity also impair the capacity of NIK1 to elicit a response against begomoviruses (Santos et al., 2009).

As Ser/Thr kinase receptors, NIKs contain all of the 11 conserved subdomains of protein kinases, in addition to specific signatures of serine/threonine kinases in subdomains VIb and VIII (Hanks et al., 1988), including the A-loop, region highly conserved among members of the LRRII-RLK subfamily and other members of the extended LRR-RLK family (Hubbard, 1997; Bellon et al., 1999; Biondi et al., 2002; Yang et al., 2002; Kornev et al., 2006). NIK1 kinase activity has been shown to be dependent on the phosphorylation status of the A-loop (Fontes et al., 2004; Carvalho et al., 2008; Santos et al., 2009). NIK1 is phosphorylated in vitro at the conserved positions Thr-474 and Thr-469, and mutations within the A-loop interfere in the NIK1 capacity of autophosphorylation (Santos et al., 2009). Replacement of Thr474 with alanine (T474A) strongly inhibits the autophosphorylation activity. This activity is completely abolished by removing the conserved Gly-473 residue in the T474A mutant to valine (G473V/T474A). In contrast, replacement of Thr-474 with a phosphomimetic aspartate residue increases autophosphorylation activity and results in constitutive activation of a NIK1 mutant receptor that it is no longer inhibited by the begomovirus NSP (Santos et al., 2009). The biological relevance of these findings has been certified by in vivo complementation assays. Ectopic expression of T474A defective kinase or G473A/T474A inactive kinase does not complement the nikl loss-of-function defect, demonstrating that Thr-474 autophosphorylation is required to transduce a defense response to begomoviruses (Santos et al.,
2009). In contrast, ectopic expression of the Arabidopsis phosphomimetic T474D mutant in tomato transgenic lines confers higher level of tolerance to tomato-infecting begomoviruses than expression of an intact NIK1 receptor (Brustolini et al., 2015). Collectively, these results implicate the phosphorylation at the essential Thr- 474 residue within the A-loop as a key regulatory mechanism for NIK activation.

The ribosomal protein L10 (RPL10), isolated through two-hybrid screening by its capacity to bind to the kinase domain of NIK1 (Rocha et al., 2008), acts as a downstream effector of the NIK-mediated antiviral response (Carvalho et al., 2008). Consistent with an RPL10 role in antiviral defense, loss of RPL10 function recapitulated the nik1 enhanced susceptibility phenotype to begomovirus infection, as the rpl10 knockout lines developed similar severe symptoms and displayed similar infection rate as nikl (Carvalho et al., 2008; Rocha et al., 2008). The RPL10 protein from Arabidopsis shows sequence similarity with the human L10 protein, also called the QM, and, like QM, displays nucleocytoplasmatic shuttling. In fact, RPL10 is localized in the cytoplasm, but is phosphorylated and redirected to the nucleus by co-expression with NIK1 (Carvalho et al., 2008). Although RPL10 binds to NIK1 in vitro and in vivo, it is not efficiently phosphorylated by NIK1 in vitro and may not serve as a direct NIK1 substrate in vivo. Nevertheless, several lines of evidence indicate that the nucleocytoplasmic shuttling of RPL10 is dependent on the phosphorylation status and kinase activity of NIK1. While the defective T474A or the inactive G473A/T474A NIK1 mutants failed to redirect RPL10 to the nuclei of cotransfected cells, expression of the hyperactive T474D mutant increased the efficiency of NIK1-mediated RPL10 nuclear localization in co-transfected cells (Carvalho et al., 2008; Santos et al., 2009). Furthermore, NIK1 does not relocate a phosphorylation-deficient mutant of RPL10 to the nucleus (Carvalho et al., 2008). Finally, mutations in the A-loop similarly affect the NIK1 capacity to mediate a phosphorylation-dependent nuclear relocalization of the RPL10 downstream component and to trigger an antiviral response (Carvalho et al., 2008; Santos et al., 2009). These data suggest that, although RPL10 is not a substrate for NIK1 protein, its nucleocytoplasmic shuttling is regulated by phosphorylation and is dependent on the kinase activity of NIK1, classifying RPL10 as a downstream effector of the NIK1-mediated signaling.

To gain further mechanistic insights into the role of NIK1 in antiviral immunity, the induced and repressed transcriptome by expressing the NIK1 phosphomimetic gain-of-function mutant T474D was assessed in Arabidopsis (Zorzatto et al., 2015). NIK1 constitutive activation does not induce the expression of typical defense marker genes associated to gene silencing, salicylic acid, or PAMP-triggered immunity (PTI) pathways but rather it down-regulates translation-related genes, causing suppres- 
sion of global in vivo translation and decreased loading of host mRNA in actively translating polysomes (PS) fractions. Likewise, induction of T474D expression through a dexamethasone-inducible promoter also impairs global translation, which was correlated with a reduction of both PS and monosome (NPS) fractions, as well as of the RNA content associated with these fractions in the T474D lines. Ectopic expression of T474D controls begomovirus infection, causing symptomless infection, delayed course of infection and reduced accumulation of viral DNA in systemically infected leaves. Additionally, in infected T474D lines, the loading of coat protein viral mRNA in actively translating polysomes is reduced as compared to that of wild type infected lines, suggesting that the translation of viral transcripts is strongly impaired by NIK1-mediated signaling. Thus, begomovirus cannot sustain high levels of viral mRNA translation in the T474D-expressing lines, indicating that suppression of global protein synthesis may effectively protect plant cells against DNA viruses (Zorzatto et al., 2015). Supporting this hypothesis, the T474D-overexpressing tomato transgenic lines are tolerant to the tomato-infecting begomoviruses ToYSV and Tomato severe rugose virus (ToSRV) (Brustolini et al., 2015), which display highly divergent genomic sequences and hence are phylogenetically separated within the two major groups of begomoviruses found in Brazil (Albuquerque et al., 2012). In addition, the gain-of-function mutant T474D from Arabidopsis functions similarly in tomato plants, as it causes a general down-regulation of translation machinery-related genes, affects translation in transgenic tomato lines and decreases viral mRNA association with the polysome fractions (Brustolini et al., 2015). Therefore, the enhanced tolerance to tomato-infecting begomovirus displayed by the T474D-expressing lines is associated with the translational control branch of the NIK-mediated antiviral responses. These observations demonstrate the potential of a sustained NIK1-mediated defense pathway to confer broad-spectrum tolerance to begomoviruses in distinct plant species. Nevertheless, in the Arabidopsis homologous system, the level of translational inhibition by the constitutive activation of NIK1 causes stunted growth in transgenic lines grown under short-day conditions, whereas, in tomato, ectopic expression of the T474D mutant does not impact development under greenhouse conditions (Brustolini et al., 2015; Zorzatto et al., 2015). As a possible explanation for this phenotype, tomato plants may not need maximal translational capacity for optimal growth under greenhouse conditions; thereby, the level of translational inhibition mediated by NIK1 activation does not reach a threshold that would impact growth. Additionally or alternatively, the T474D-mediated translational suppression provokes a constant perception of stress in the transgenic lines, which, in turn, promotes acclimation to maintain normal growth under greenhouse conditions. Therefore, the intrinsic capacity of agronomically relevant crops to with- stand the deleterious effect from the suppression of global translation is a relevant agronomic trait to be considered for engineering the NIK1-mediated resistance against begomoviruses in crops.

Recent progress towards directly connecting the NIK1-mediated signaling pathway with the downregulation of translational-machinery-related genes includes the isolation of a transcription factor harboring a MYB domain, named L10-INTERACTING MYB DOMAINCONTAINING PROTEIN (LIMYB), which interacts with RPL10 in the nucleus of plant cells (Zorzatto et al., 2015). The interaction between LIMYB and RPL10 results in the formation of a transcriptional repressor complex that specifically suppresses the expression of ribosomal protein (RP) genes through the binding of LIMYB on RP gene promoters. This RP down-regulation leads to protein synthesis inhibition and enhanced tolerance to the begomovirus $\mathrm{CaLCuV}$. T474D also down-regulates the expression of the same sub-set of LIMYB-regulated RP genes but requires the LIMYB function to repress RP gene expression. In addition, the loss of LIMYB function releases the repression of translation-related genes and increases susceptibility to $\mathrm{CaLCuV}$ infection (Zorzatto et al., 2015). Collectively, these results provide both genetic and biochemical evidence that the LIMYB gene functions as a downstream component of the NIK1-mediated signaling pathway linking NIK1 activation to global translation suppression and tolerance to begomiviruses.

Despite the advances in the elucidation of NIKmediated antiviral signaling pathway, there is a complete lack of information on the critical early event that triggers the NIK1 signaling and transduction, which culminates with the suppression of host global translation as an antiviral response. Recently, a comparison between the transcriptomes induced by begomovirus infection and by expression of the gain-of-function T474D mutant revealed that begomovirus infection is the activating stimulus of NIK1-mediated defense, although the molecular basis for this elicitation is still unknown (Machado et al., 2015; Zorzatto et al., 2015). A mechanistic model for a NIK1mediated defense signaling pathway and its interaction with the begomovirus NSP is illustrated in Figure 3. Upon begomovirus infection, the extracellular domain of NIK undergoes oligomerization, allowing the intracellular kinase domains to transphosphorylate on a key threonine residue at position 474 (T474) and to activate one another (Santos et al., 2009). Alternatively or additionally, NIK1 may serve as a co-receptor for a defense-signaling cascade and interacts with an unidentified ligand-dependent LRRRLK receptor in response to virus infection. The phosphorylation-dependent activation of NIK leads to the phosphorylation of RPL10 and the phosphorylated RPL10 is translocated to the nucleus, where it interacts with LIMYB to fully down-regulate translation machinery-related genes, leading to host global translation suppression that affects 


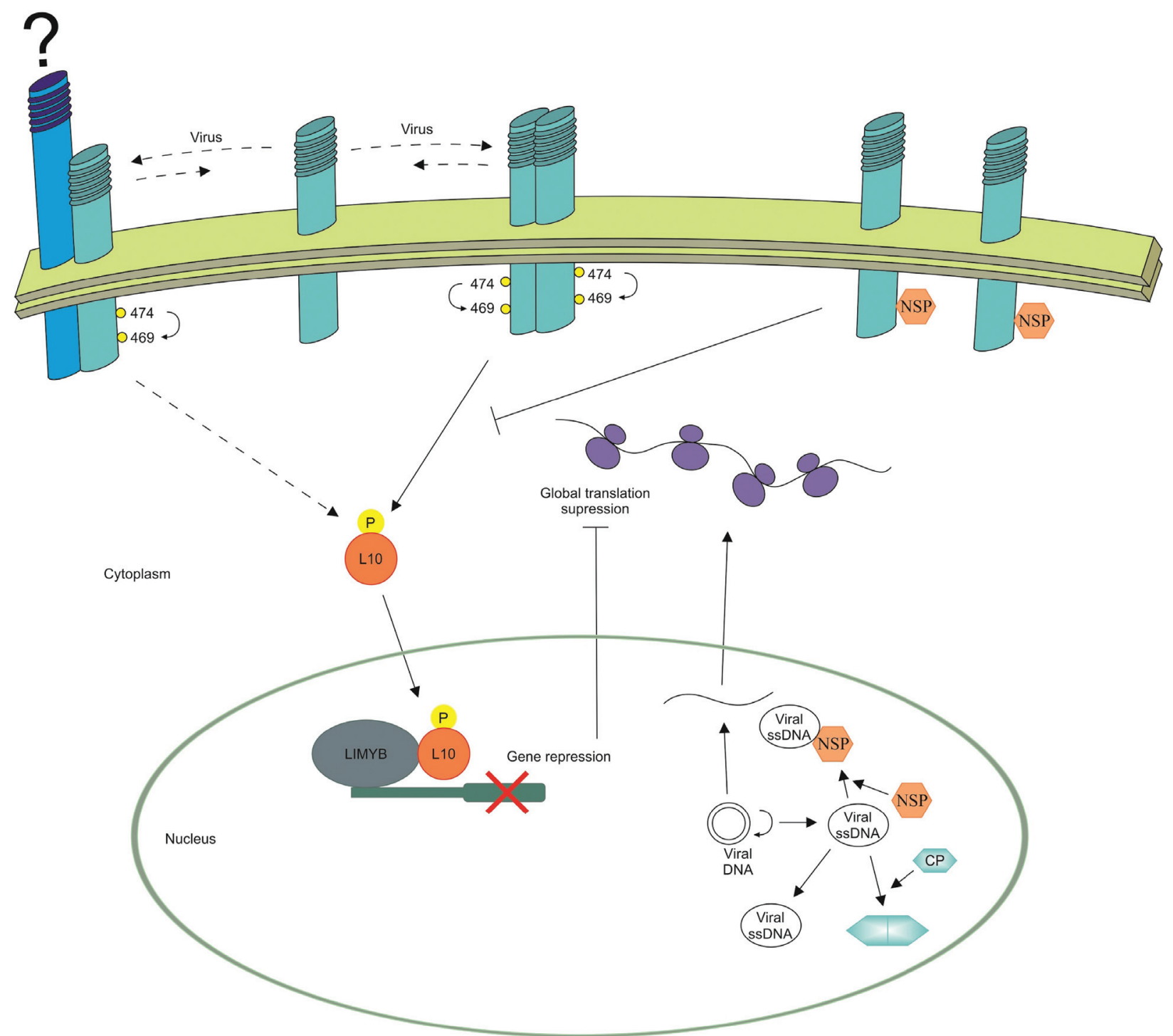

Figure 3 - Mechanistic overview of the antiviral defense pathway mediated by NIK1. Upon virus infection, NIK1 forms a homodimer and is activated through transphosphorylation of its kinase domain at the Thr-474 residue. Alternatively, NIK1 binds to an unknown ligand-binding LRR-RLK in a stimulus-dependent manner. The activation of NIK1 triggers the phosphorylation of RPL10 that, in turn, is transported to the nucleus. In the nuclear compartment, RPL10 interacts with LIMYB, which binds to the promoter of ribosomal protein (RP) genes to repress their transcription. As a consequence, a suppression of host global protein synthesis is observed, which also impairs translation of viral mRNA. As a defense countermeasure, NSP of begomoviruses binds and inhibits the NIK1 kinase activity, which impairs the RPL10 phosphorylation. Thus, RPL10 is retained in the cytosol, enhancing begomovirus infection. As begomoviruses have single-stranded circular DNA genomes, they replicate in the nucleus of the infected cells by double-stranded DNA intermediaries, which are also template for transcription of viral mRNAs. NSP binds to nascent viral DNA and facilitates the traffic of viral DNA from the nucleus to the cytoplasm by an unclear mechanism.

the translation of the begomovirus mRNAs (Carvalho et al., 2008; Zorzatto et al., 2015). Thus, this down-regulation of cytosolic translation underlies at least partially the molecular mechanisms involved in the NIK1-mediated antiviral defense, which can be suppressed by binding of NSP to the NIK1 kinase domain.

\section{Conclusions}

Due to the agronomic importance of plant virus as pathogens, the development of antiviral strategies aiming crop protection has been continually on focus. In this con- text, the identification and characterization of host factors targeted during infection constitute one of the most important goals of the virology research. Due to their limited viral genome-encoded functions, the viruses have developed diverse strategies to hijack the host translation apparatus to quickly and efficiently produce viral proteins. Thus, translation repression has emerged as a plant antiviral defense strategy to impair the translation of viral proteins and could contribute as targets for the development of resistance strategy for virus control. In fact, plant RNA viruses interact tightly with the host protein synthesis machinery such that 
host translation initiation factor-encoding genes can function as recessive resistance genes. Furthermore, the translational repression activity of the effector AGO has been recently demonstrated to play a role in the antiviral RNA silencing mechanism. Finally, as a new paradigm in plant antiviral immunity, the activation of the immune receptor NIK1-mediated suppression of translation has been demonstrated to be effective in controlling begomovirus infections. These examples substantiate the notion that impairing viral mRNA translation (specifically or globally) constitutes a promising strategy for plant protection against viruses.

\section{Acknowledgments}

This work was supported by the Conselho Nacional de Desenvolvimento Científico e Tecnológico (grants 573600/2008-2 and 447578/2014-6 to EPBF) and the Fundação de Amparo à Pesquisa do Estado de Minas Gerais (grants CBB-APQ-03175-13 and CBB-APQ-01491-14 to EPBF). IPC was supported by a CAPES graduate fellowship and JPBM is a recipient of a CAPES postdoctoral fellowship.

\section{References}

Aitken CE and Lorsch JR (2012) A mechanistic overview of translation initiation in eukaryotes. Nat Struct Mol Biol 19:568-576.

Albar L, Bangratz-Reyser M, Hébrard E, Ndjiondjop MN, Jones $M$ and Ghesquière A (2006) Mutations in the eIF(iso) $4 \mathrm{G}$ translation initiation factor confer high resistance of rice to Rice yellow mottle virus. Plant J 47:417-426.

Albuquerque LC, Varsani A, Fernandes FR, Pinheiro B, Martin DP, Ferreira PTO, Lemos TO and Inoue-Nagata AK (2012) Further characterization of tomato-infecting begomoviruses in Brazil. Arch Virol 157:747-752.

Andrade M, Abe Y, Nakahara KS and Uyeda I (2009) The cyv-2 resistance to Clover yellow vein virus in pea is controlled by the eukaryotic initiation factor 4E. J Gen Plant Pathol 75:241-249.

Aukerman MJ and Sakai H (2003) Regulation of flowering time and floral organ identity by a microRNA and its APETALA2-like target genes. Plant Cell 15:2730-2741.

Azevedo J, Garcia D, Pontier D, Ohnesorge S, Yu A, Garcia S, Braun L, Bergdoll M, Hakimi MA, Lagrange T, et al. (2010) Argonaute quenching and global changes in Dicer homeostasis caused by a pathogen-encoded GW repeat protein. Genes Dev 24:904-915.

Baumberger N and Baulcombe DC (2005) Arabidopsis ARGONAUTE1 is an RNA Slicer that selectively recruits microRNAs and short interfering RNAs. Proc Natl Acad Sci U S A 102:11928-11933.

Baumberger N, Tsai CH, Lie M, Havecker E and Baulcombe DC (2007) The Polerovirus silencing suppressor P0 targets ARGONAUTE proteins for degradation. Curr Biol 17:1609-1614.

Beauchemin C and Laliberte JF (2007) The poly(A) binding protein is internalized in virus-induced vesicles or redistributed to the nucleolus during Turnip mosaic virus infection. $\mathrm{J}$ Virol 81:10905-10913.

Bellon S, Fitzgibbon MJ, Fox T, Hsiao H-M and Wilson KP (1999) The structure of phosphorylated P38g is monomeric and reveals a conserved activation-loop conformation. Structure 7:1057-1065.

Bhattacharjee S, Zamora A, Azhar MT, Sacco MA, Lambert LH and Moffett P (2009) Virus resistance induced by NB-LRR proteins involves Argonaute4-dependent translational control. Plant J 58:940-951.

Biondi RM, Komander D, Thomas CC, Lizcano JM, Deak M, Alessi DR and van Aalten DM (2002) High resolution crystal structure of the human PDK1 catalytic domain defines the regulatory phosphopeptide docking site. EMBO J 21:4219-4228.

Bologna NG and Voinnet O (2014) The diversity, biogenesis, and activities of endogenous silencing small RNAs in Arabidopsis. Annu Rev Plant Biol 65:473-503.

Bortolamiol D, Pazhouhandeh M, Marrocco K, Genschik P and Ziegler-Graff V (2007) The Polerovirus F box protein P0 targets ARGONAUTE1 to suppress RNA silencing. Curr Biol 17:1615-1621.

Brodersen P, Sakvarelidze-Achard L, Bruun-Rasmussen M, Dunoyer P, Yamamoto YY, Sieburth L and Voinnet O (2008) Widespread translational inhibition by plant miRNAs and siRNAs. Science 320:1185-1190.

Brustolini OJB, Machado JPB, Condori-Apfata JA, Coco D, Deguchi M, Loriato VA, Pereira W, Alfenas-Zerbini P, Zerbini FM, Inoue-Nagata AK, et al. (2015) Sustained NIK-mediated antiviral signalling confers broad-spectrum tolerance to begomoviruses in cultivated plants. Plant Biotechnol J 13:1300-1311.

Burgyán J and Havelda Z (2011) Viral suppressors of RNA silencing. Trends Plant Sci 16:265-272.

Carbonell A and Carrington JC (2015) Antiviral roles of plant ARGONAUTES. Curr Opin Plant Biol 27:111-117.

Carvalho CM, Santos AA, Pires SR, Rocha SR, Saraiva DI, Machado JP, Mattos EC, Fietto LG and Fontes EP (2008) Regulated nuclear trafficking of $\mathrm{rpL10A}$ mediated by NIK1 represents a defense strategy of plant cells against viruses. PLoS Pathog 4:e1000247.

Chen X (2004) A microRNA as a translational repressor of APETALA2 in Arabidopsis flower development. Science 303:2022-2025.

Chiu MH, Chen IH, Baulcombe DC and Tsai CH (2010) The silencing suppressor P25 of Potato virus $\mathrm{X}$ interacts with Argonaute1 and mediates its degradation through the proteasome pathway. Mol Plant Pathol 11:641-649.

Contreras-Paredes CA, Silva-Rosales L, Daròs JA, AlejandriRamírez ND and Dinkova TD (2013) The absence of eukaryotic initiation factor eIF(iso)4E affects the systemic spread of a tobacco etch virus isolate in Arabidopsis thaliana. Mol Plant-Microbe Interact J 26:461-470.

Csorba T, Lozsa R, Hutvagner G and Burgyan J (2010) Polerovirus protein $\mathrm{P} 0$ prevents the assembly of small RNAcontaining RISC complexes and leads to degradation of ARGONAUTE1. Plant J 62:463-472.

Csorba T, Kontra L and Burgyan J (2015) Viral silencing suppressors: Tools forged to fine-tune host-pathogen coexistence. Virology 479-480:85-103. 
De Ronde D, Butterbach P and Kormelink R (2014) Dominant resistance against plant viruses. Front Plant Sci 5:307.

Derrien B, Baumberger N, Schepetilnikov M, Viotti C, De Cillia J, Ziegler-Graff V, Isono E, Schumacher K and Genschik P (2012) Degradation of the antiviral component ARGONAUTE1 by the autophagy pathway. Proc Natl Acad Sci U S A 109:15942-15946.

Dievart A and Clark SE (2004) LRR-containing receptors regulating plant development and defense. Development 131:251-261.

Ding SW (2010) RNA-based antiviral immunity. Nat Rev Immunol 10:632-644.

Eskelin K, Hafren A, Rantalainen KI and Makinen K (2011) Potyviral VPg enhances viral RNA Translation and inhibits reporter mRNA translation in planta. J Virol 85:9210-9221.

Fang X and Qi Y (2016) RNAi in Plants: An Argonaute-centered view. Plant Cell 28:272-285.

Fátyol K, Ludman M and Burgyán J (2016) Functional dissection of a plant Argonaute. Nucleic Acids Res 44:1384-1397.

Fontes EPB, Santos AA, Luz DF, Waclawovsky AJ and Chory J (2004) The geminivirus nuclear shuttle protein is a virulence factor that suppresses transmembrane receptor kinase activity. Genes Dev 18:2545-2556.

Fukaya T and Tomari Y (2012) MicroRNAs mediate gene silencing via multiple different pathways in Drosophila. Mol Cell 48:825-836.

Fusaro AF, Correa RL, Nakasugi K, Jackson C, Kawchuk L, Vaslin MF and Waterhouse PM (2012) The Enamovirus P0 protein is a silencing suppressor which inhibits local and systemic RNA silencing through AGO1 degradation. Virology 426:178-187.

Galvez LC, Banerjee J, Pinar H and Mitra A (2014) Engineered plant virus resistance. Plant Sci 228:11-25.

Gandikota M, Birkenbihl RP, Höhmann S, Cardon GH, Saedler H and Huijser P (2007) The miRNA156/157 recognition element in the 3' UTR of the Arabidopsis SBP box gene SPL3 prevents early flowering by translational inhibition in seedlings. Plant J 49:683-693.

Gao Z, Eyers S, Thomas C, Ellis N and Maule A (2004a) Identification of markers tightly linked to sbm recessive genes for resistance to Pea seed-borne mosaic virus. Theor Appl Genet 109 488-494.

Gao Z, Johansen E, Eyers S, Thomas CL, Noel Ellis TH and Maule AJ (2004b) The potyvirus 9 recessive resistance gene, sbm1, identifies a novel role for translation initiation factor 10 eIF4E in cell-to-cell trafficking. Plant J 40:376-385.

Garcia-Ruiz H, Carbonell A, Hoyer JS, Fahlgren N, Gilbert KB, Takeda A, Giampetruzzi A, Garcia Ruiz MT, McGinn MG, Lowery N, et al. (2015) Roles and programming of Arabidopsis ARGONAUTE proteins during turnip mosaic virus infection. PLoS Pathog 11:e1004755.

Ghoshal B and Sanfaçon H (2014) Temperature-dependent symptom recovery in Nicotiana benthamiana plants infected with tomato ringspot virus is associated with reduced translation of viral RNA2 and requires ARGONAUTE 1. Virology 456-457:188-197.

Ghoshal B and Sanfaçon H (2015) Symptom recovery in virus-infected plants: Revisiting the role of RNA silencing mechanisms. Virology 479-480:167-179.
Giner A, Lakatos L, Garcia-Chapa M, Lopez-Moya JJ and Burgyán J (2010) Viral protein inhibits RISC activity by argonaute binding through conserved WG/GW motifs. PLoS Pathog 6:e1000996.

Goodfellow IG and Roberts LO (2008) Eukaryotic initiation factor 4E. Int J Biochem Cell Biol 40:2675-2680.

Gururani MA, Venkatesh J, Upadhyaya CP, Nookaraju A, Pandeyc SK and Park SW (2012) Plant disease resistance genes: Current status and future directions. Physiol Mol Plant Pathol 78:51-65.

Hafren A, Eskelin K and Mäkinen K (2013) Ribosomal protein P0 promotes Potato virus A infection and functions in viral translation together with $\mathrm{VPg}$ and $\mathrm{eIF}$ (iso)4E. J Virol 87:4302-4312.

Hanks SK, Quinn AM and Hunter T (1988) The protein kinase family: Conserved features and deduced phylogeny of the catalytic domains. Science 241:42-52.

Hanley-Bowdoin L, Bejarano ER, Robertson D and Mansoor S (2013) Geminiviruses: Masters at redirecting and reprogramming plant processes. Nat Rev Microbiol 11:777-788.

Hebrard E, Poulicard N, Gerard C, Traore O, Wu HC, Albar L, Fargette D, Bessin Y and Vignols F (2010) Direct interaction between the Rice yellow mottle virus (RYMV) VPg and the central domain of the rice eIF(iso)4G1 factor correlates with rice susceptibility and RYMV virulence. Mol Plant Microbe Interact 23:1506-1513.

Hinnebusch AG (2014) The scanning mechanism of eukaryotic translation initiation. Annu Rev Biochem 83:779-812.

Huang TS, Wei T, Laliberte JF and Wang A (2010) A host RNA helicase-like protein, AtRH8, interacts with the potyviral genome-linked protein, VPg, associates with the virus accumulation complex, and is essential for infection. Plant Physiol 152:255-266.

Hubbard SR (1997) Crystal structure of the active insulin receptor tyrosine kinase in complex with peptide substrate and ATP analog. EMBO J 16:5573-5581.

Huntzinger E and Izaurralde E (2011) Gene silencing by microRNAs: Contributions of translational repression and mRNA decay. Nat Rev Genet 12:99-110.

Hwang J, Oh CS and Kang BC (2013) Translation elongation factor 1B (eEF1B) is an essential host factor for Tobacco mosaic virus infection in plants. Virology 439:105-114.

Iwakawa HO and Tomari Y (2013) Molecular insights into microRNAmediated translational repression in plants. Mol Cell 52:591-601.

Jackson RJ, Hellen CU and Pestova TV (2010) The mechanism of eukaryotic translation initiation and principles of its regulation. Nat Rev Mol Cell Biol 11:113-127.

Jones-Rhoades MW, Bartel DP and Bartel B (2006) MicroRNAs and their regulatory roles in plants. Annu Rev Plant Biol 57:19-53.

Julio E, Cotucheau J, Decorps C, Volpatti R, Sentenac C, Candresse T and Dorlhac de Borne F (2015) A eukaryotic translation initiation factor $4 \mathrm{E}(\mathrm{eIF} 4 \mathrm{E})$ is responsible for the "va" tobacco recessive resistance to potyviruses. Plant Mol Biol Rep 33:609-623.

Kamthan A, Chaudhuri A, Kamthan M and Datta A (2015) Small RNAs in plants: Recent development and application for crop improvement. Front Plant Sci 6:208.

Kang BC, Yeam I, Frantz JD, Murphy JD and Jahn MM (2005a) The pvr1 locus in Capsicum encodes a translation initiation 
factor eIF4E that interacts with Tobacco etch virus VPg. Plant J 42:392-405.

Kang BC, Yeam I and Jahn MM (2005b) Genetics of plant virus resistance. Annu Rev Phytopathol 43:581-621.

Karran RA and Sanfaçon H (2014) Tomato ringspot virus coat protein binds to ARGONAUTE 1 and suppresses the translation repression of a reporter gene. Mol Plant Microbe Interact 27:933-943.

Kasschau KD and Carrington JC (1998) A counterdefensive strategy of plant viruses: Suppression of posttranscriptional gene silencing. Cell 95:461-470.

Khan MA, Miyoshi H, Gallie DR and Goss DJ (2008) Potyvirus genome-linked protein, Vpg, directly affects wheat germ in vitro translation: Interactions with translation initiation factors eIF4F and eIFiso4F. J Biol Chem 283:1340-1349.

Kornev AP, Haste NH, Taylor SS and Eyck LFT (2006) Surface comparision of active and inactive protein kinases identifies a conserved activation mechanism. Proc Natl Acad Sci USA 103:17783-17788.

Krol J, Loedige I and Filipowicz W (2010) The widespread regulation of microRNA biogenesis, function and decay. Nat Rev Genet 11:597-610.

Lanet E, Delannoy E, Sormani R, Floris M, Brodersen P, Crété P, Voinnet $\mathrm{O}$ and Robaglia C (2009) Biochemical evidence for translational repression by Arabidopsis microRNAs. Plant Cell 21:1762-1768.

Lee JH, Muhsin M, Atienza GA, Kwak DY, Kim SM, De Leon TB, Angeles ER and Coloquio E (2010). Single nuclieotide polymorphisms in a gene for translation initiation factor (eIF4G) of rice (Oryza sativa) associated with resistance to rice tungro spherical virus. Mol Plant-Microbe Interact J 23:29-38.

Lellis AD, Kasschau KD, Whitham SA and Carrington JC (2002) Loss-of-susceptibility mutants of Arabidopsis thaliana reveal an essential role for eIF(iso)4E during potyvirus infection. Curr Biol 12:1046-1051.

Léonard S, Plante D, Wittmann S, Daigneault N, Fortin MG and Laliberté JF (2000) Complex formation between potyvirus VPg and translation eukaryotic initiation factor 4E correlates with virus infectivity. J Virol 74:7730-7737.

Li S, Liu L, Zhuang X, Yu Y, Liu X, Cui X, Ji L, Pan Z, Cao X, Mo B, et al. (2013) MicroRNAs inhibit the translation of target mRNAs on the endoplasmic reticulum in Arabidopsis. Cell 153:562-574.

Llave C, Xie Z, Kasschau KD and Carrington JC (2002) Cleavage of Scarecrow-like mRNA targets directed by a class of Arabidopsis miRNA. Science 297:2053-2056.

Ma X, Nicole MC, Meteignier LV, Hong N, Wang G and Moffett P (2015) Different roles for RNA silencing and RNA processing components in virus recovery and virus-induced gene silencing in plants. J Exp Bot 66:919-932.

Machado JPB, Brustolini OJB, Mendes GC, Santos AA and Fontes EPB (2015) NIK1, a host factor specialized in antiviral defense or a novel general regulator of plant immunity? BioEssays 37:1236-1242.

Mallory A and Vaucheret H (2010) Form, function, and regulation of ARGONAUTE proteins. Plant Cell 22:3879-3889.

Mandadi KK and Scholthof K-BG (2013) Plant immune responses against viruses: How does a virus cause disease? Plant Cell 25:1489-1505.
Mariano AC, Andrade MO, Santos AA, Carolino SMB, Oliveira ML, Baracat-Pereira MC, Brommonshenkel SH and Fontes EP (2004) Identification of a novel receptor-like protein kinase that interacts with a geminivirus nuclear shuttle protein. Virology 318:24-31.

Martinez de Alba AE, Elvira-Matelot E and Vaucheret H (2013) Gene silencing in plants: A diversity of pathways. Biochim Biophys Acta 1829:1300-1308.

Matsuda D and Dreher TW (2004) The tRNA-like structure of Turnip yellow mosaic virus RNA is a 3'-translational enhancer. Virology 321:36-46.

Michon T, Estevez Y, Walter J, German-Retana S and Le Gall O (2006) The potyviral virus genome-linked protein VPg forms a ternary complex with the eukaryotic initiation factors eIF4E and eIF4G and reduces eIF4E affinity for a mRNA cap analogue. FEBS J 273:1312-1322.

Nicaise V (2014) Crop immunity against viruses: Outcomes and future challenges. Front Plant Sci 5:660.

Nicaise V, German-Retana S, Sanjuan R, Dubrana MP, Mazier M, Maisonneuve B, Candresse T, Caranta $\mathrm{C}$ and LeGall $\mathrm{O}$ (2003) The eukaryotic translation initiation factor 4E controls lettuce susceptibility to the Potyvirus Lettuce mosaic virus. Plant Physiol 132:1272-1282.

Nicaise V, Gallois JL, Chafiai F, Allen LM, Schurdi-Levraud V, Browning KS, Candresse T, Caranta C, Le Gall O and German-Retana S (2007) Coordinated and selective recruitment of eIF4E and eIF4G factors for potyvirus infection in Arabidopsis thaliana. FEBS Lett 581:1041-1046.

Nieto C, Morales M, Orjeda G, Clepet C, Monfort A, Sturbois B, Puigdomènech $\mathrm{P}$, Pitrat $\mathrm{M}$, Caboche $\mathrm{M}$, Dogimont $\mathrm{C}$, et al. (2006) An eIF4E allele confers resistance to an uncapped and non-polyadenylated RNA virus in melon. Plant $\mathrm{J}$ 48:452-462.

Osman TA and Buck KW (1997) The Tobacco mosaic virus RNA polymerase complex contains a plant protein related to the RNA-binding subunit of yeast eIF-3. J Virol 71:6075-6082.

Patrick RM and Browning KS (2012) The eIF4F and eIFiso4F complexes of plants: An evolutionary perspective. Comp Funct Genomics 2012:287814.

Pfaff J and Meister G (2013) Argonaute and GW182 proteins: An effective alliance in gene silencing. Biochem Soc Trans 41:855-860.

Plante D, Viel C, Leonard S, Tampo H, Lalibertéb J-F and Fortin MG (2004) Turnip mosaic virus VPg does not disrupt the translation initiation complex but interfere with cap binding. Physiol Mol Plant Pathol 64:219-226.

Pumplin N and Voinnet O (2013) RNA silencing suppression by plant pathogens: Defence, counter-defence and countercounter-defence. Nat Rev Microbiol 11:745-760.

Rajamäki ML and Valkonen JPT (2009) Control of nuclear and nucleolar localization of nuclear inclusion protein a of picorna-like Potato virus A in Nicotiana species. Plant Cell 21:2485-2502.

Ritzenthaler C (2005) Resistance to plant viruses: Old issue, news answers? Curr Opin Biotechnol 16:118-122.

Robaglia C and Caranta C (2006) Translation initiation factors: A weak link in plant RNA virus infection. Trends Plant Sci 11:40-45.

Rocha CS, Santos AA, Machado JPB and Fontes EPB (2008) The ribosomal protein L10/QM-like protein is a component of 
the NIK-mediated antiviral signaling. Virology 380:165-169.

Ruffel S, Dussault MH, Palloix A, Moury B, Bendahmane A, Robaglia C and Caranta C (2002) A natural recessive resistance gene against Potato virus $\mathrm{Y}$ in pepper corresponds to the eukaryotic initiation factor 4E (eIF4E). Plant $\mathrm{J}$ 32:1067-1075.

Ruffel S, Gallois JL, Lesage ML and Caranta C (2005) The recessive potyvirus resistance gene pot- 1 is the tomato orthologue of the pepper pvr2-eIF4E gene. Mol Genet Genomics 274:346-353.

Ruffel S, Gallois JL, Moury B, Robaglia C, Palloix A and Caranta C (2006) Simultaneous mutations in translation initiation factors eIF4E and eIF(iso)4E are required to prevent pepper veinal mottle virus infection of pepper. J Gen Virol 87:2089-2098.

Sakamoto T, Deguchi M, Brustolini OJB, Santos AA, Silva FF and Fontes EP (2012) The tomato RLK superfamily: Phylogeny and functional predictions about the role of the LRRII-RLK subfamily in antiviral defense. BMC Plant Biol 12:229.

Sanfaçon H (2015) Plant translation factors and virus resistance. Viruses 7:3392-3419.

Santos AA, Carvalho CM, Florentino LH, Ramos HJO and Fontes EP (2009) Conserved threonine residues within the A-loop of the receptor NIK differentially regulate the kinase function required for antiviral signaling. PLoS One 4:e5781.

Schaad MC, Anderberg RJ and Carrington JC (2000) Strainspecific interaction of the tobacco etch virus NIa protein with the translation initiation factor eIF4E in the yeast twohybrid system. Virology 273:300-306.

Shiu S-H and Bleecker AB (2001) Receptor-like kinases from Arabidopsis form a monophyletic gene family related to animal receptor kinases. Proc Natl Acad Sci U S A 98:10763-10768.

Stein N, Perovic D, Kumlehn J, Pellio B, Stracke S, Streng S, Ordon F and Graner A (2005) The eukaryotic translation initiation factor $4 \mathrm{E}$ confers multiallelic recessive Bymovirus resistance in Hordeum vulgare (L.). Plant J 42:912-922.

Szabo EZ, Manczinger M, Goblos A, Kemeny L and Lakatos L (2012) Switching on RNA silencing suppressor activity by restoring argonaute binding to a viral protein. J Virol 86 8324-8327.

Szittya G and Burgyan J (2013) RNA interference-mediated intrinsic antiviral immunity in plants. Curr Top Microbiol Immunol 371:153-181.

Tang G, Reinhart BJ, Bartel DP and Zamore PD (2003) A biochemical framework for RNA silencing in plants. Genes Dev 17:49-63.

Thivierge K, Cotton S, Dufresne PJ, Mathieu I, Beauchemin C, Ide C, Fortin MG and Laliberté JF (2008) Eukaryotic elongation factor 1A interacts with Turnip mosaic virus RNAdependent RNA polymerase and VPg-Pro in virus-induced vesicles. Virology 377:216-225.

Truniger V and Aranda MA (2009) Recessive resistance to plant viruses. Adv Virus Res 75:119-159.

Vargason JM, Szittya G, Burgyan J and Tanaka Hall TM (2003) Size selective recognition of siRNA by an RNA silencing suppressor. Cell 115:799-811.
Walsh D and Mohr I (2011) Viral subversion of the host protein synthesis machinery. Nat Rev Microbiol 9:860-875.

Wang A (2015) Dissecting the molecular network of virus-plant interactions: The complex roles of host factors. Annu Rev Phytopathol 53:45-66.

Wang A and Krishnaswamy S (2012) Eukaryotic translation initiation factor $4 \mathrm{E}-$ mediated recessive resistance to plant viruses and its utility in crop improvement. Mol Plant Pathol 13:795-803.

Wang H-LV and Chekanova JA (2016) Small RNAs: Essential regulators of gene expression and defenses against environmental stresses in plants. Wiley Interdiscip Rev RNA 7:356-381.

Wilczynska A and Bushell M (2015) The complexity of miRNAmediated repression. Cell Death Differ 22:22-33.

Wittmann S, Chatel H, Fortin MG and Laliberte JF (1997) Interaction of the viral protein genome linked of Turnip mosaic potyvirus with the translational eukaryotic initiation factor (iso)4E of Arabidopsis thaliana using the yeast two-hybrid system. Virology 234:84-92.

Yamaji Y, Kobayashi T, Hamada K, Sakurai K, Yoshii A, Suzuki M, Namba S and Hibi T (2006) In vivo interaction between Tobacco mosaic virus RNA-dependent RNA polymerase and host translation elongation factor 1A. Virology 347:100-108.

Yang J, Cron P, Thompson V, Good VM, Hess D, Hemmings BA and Barford D (2002) Molecular mechanism for the regulation of protein kinase B/Akt by hydrophobic motif phosphorylation. Mol Cell 9:1227-1240.

Yang L, Wu G and Poethig RS (2012) Mutations in the GWrepeat protein SUO reveal a developmental function for microRNA-mediated translational repression in Arabidopsis. Proc Natl Acad Sci U S A 109:315-320.

Ye K, Malinina L and Patel DJ (2003) Recognition of small interfering RNA by a viral suppressor of RNA silencing. Nature 426:874-878.

Yoshii M, Nishikiori M, Tomita K, Yoshioka N, Kozuka R, Naito S and Ishikawa M (2004) The Arabidopsis Cucumovirus multiplication 1 and 2 loci encode translation initiation factors 4E and 4G. J Virol 78:6102-6111.

Zhang C, Wu Z, Li Y and Wu J (2015) Biogenesis, function, and applications of virus-derived small RNAs in plants. Front Microbiol 6:1237.

Zhang X, Yuan YR, Pei Y, Lin SS, Tuschl T, Patel DJ and Chua NH (2006) Cucumber mosaic virus-encoded 2b suppressor inhibits Arabidopsis Argonaute1 cleavage activity to counter plant defense. Genes Dev 20:3255-3268.

Zhang X, Zhang X, Singh J, Li D and Qu F (2012) Temperature-dependent survival of Turnip crinkle virus-infected arabidopsis plants relies on an RNA silencing-based defense that requires dc12, AGO2, and HEN1. J Virol 86:6847-6854.

Zorzatto C, Machado JPB, Lopes KVG, Nascimento KJT, Pereira WA, Brustolini OJ, Reis PA, Calil IP, Deguchi M, Sachetto-Martins G, et al. (2015) NIK1-mediated translation suppression functions as a plant antiviral immunity mechanism. Nature 520:679-682.

Associate Editor: Marcio de Castro Silva Filho

License information: This is an open-access article distributed under the terms of the Creative Commons Attribution License (type CC-BY), which permits unrestricted use, distribution and reproduction in any medium, provided the original article is properly cited. 